\title{
水资源可持续利用与水资源管理
}

\author{
宋光辉 \\ 新疆塔里木河流域巴音郭楞管理局开都一孔雀河管理处开都河中游管理站，新疆 巴州 841305
}

[摘要]目前的经济社会发展不断前进, 人们对于自然环境的破坏也随着粗放式的经济社会发展方式变得更加严重, 对于空气、 土壤、水资源的污染和破坏给人类社会带来了很大的威胁，可以说人类文明的可持续发展必须要合理的、科学的开发和利用 各类资源。特别是宝贵的、珍惜的水资源, 水资源是所有动植物生存必不可少的一种资源, 同时在经济社会发展中发挥着极 为关键的作用。而在目前的生活和生产的过程中, 人们对于水资源的损耗和浪费是比较突出的, 对水资源的利用率比较低, 在我国城镇化水平不断提升、城镇化率不断加大的情况下, 人们的生活和生产特别是一些重工业以及化学工业对水资源的污 染和破坏日益严重, 地区之间的水资源供给和需求之间的矛盾日益突出。在这个背景下对于水资源的科学、高效的管理就显 得极为关键和重要, 文章梳理了当前的社会环境下可持续的水资源管理和水资源保护方面的具体实施情况, 还强调了水资源 管理工作的重要性，希望可以为相关部门提供参考，进一步的提高社会对水资源的利用效率。 [关键词]水资源; 可持续利用; 管理

DOI：10.33142/hst.v3i4.2254 中图分类号: TV213.4 文献标识码: A

\section{Sustainable Utilization and Management of Water Resources}

SONG Guanghui

Middle Reaches of Kaidu River Management Station, Kaidu Kongque River Management Office, Bayingolin Administration Bureau, Xinjiang Tarim River Basin, Bazhou, Xinjiang, 841305, China

\begin{abstract}
With development of economy and society, people's destruction of natural environment has become more and more serious with extensive way of economic and social development. The pollution and destruction of air, soil and water resources have brought great threat to human society. It can be said that sustainable development of human civilization must be reasonable and scientific development and utilization of all kinds of resources, especially precious and treasured water resources, which are indispensable for the survival of all animals and plants and play an extremely crucial role in the economic and social development. In the current process of life and production, people are more prominent in the loss and waste of water resources and the utilization rate of water resources is relatively low. With continuous improvement of urbanization level and increasing urbanization rate in China, people's life and production, especially some heavy industry and chemical industry, which are increasingly serious in pollution and destruction of water resources and the water between regions. The contradiction between resource supply and demand is increasingly prominent. In this context, the scientific and efficient management of water resources is extremely critical and important. This paper combs the specific implementation of sustainable water resources management and water resources protection in current social environment and also emphasizes importance of water resources management, hoping to provide reference for departments to further improve utilization efficiency of water resources in society.
\end{abstract}

Keywords: water resources; sustainable utilization; management

\section{引言}

目前, 地球上有主要两种形式的水资源存在方式, 一种是地表水资源, 另外一种就是与之相对的地下水资源。其中, 地表水就是我们经常见到的江河湖等等。而地下水资源我们通常情况下难以见到, 因为它深藏在地下, 地下水的形成需 要地表水以及降水的长期下渗补充, 需要一个非常漫长的形成过程。随着人类社会的迅速发展, 人们对于水资源的开发 和利用是不断提高的, 大量的淡水资源被使用和浪费, 导致了很严重的水资源短缺的问题, 给人类社会的发展带来了很 大的威胁, 在这种现实情况下必须要不断的研究和探索科学合理的水资源的循环、可持续利用以及水资源的管理。

\section{1 我国水资源的主要特点}

\section{1 循环性和有限性}

水资源具有循环性的特点, 地表水不断蒸发通过降水可对地表水以及地下水进行补给。此外, 地球上的水资源是 
有限的, 尤其是淡水资源只占全球总水量的 2. $5 \%$ 。我国目前的淡水资源总量占全球水资源的 $6 \%$, 是严重缺水国家。

\section{2 分布不均匀和不可代替性}

中国的国土十分辽阔，东西南北的跨度非常大，而且包含了很多不同种类的地形地貌、气候特征等等，在水资源 的分布情况上来看各个不同的地区之间也存在着非常大的差异, 在我国的东南地区, 降雨量是比较充沛的, 再加上江 和湖非常多可以进行水资源的存储, 所以说南方的水资源要比北方充足的多。此外, 在东西方上面也有这种明显的差 别。还需要注意到的是我国的水资源在分配方面也十分的不均衡, 易受某些天气、气候的影响, 而出现严重的干旱和 洪涝等自然灾害。水资源在一切生命当中都是最根本和最基础的, 也是最不可替代的, 生命离开了水资源就难以存活, 没有了水资源也就没有了庄稼和粮食, 一些工业生产也无法进行。所以说, 水资源需要适度利用, 过多或者过少的水 资源都会影响人类社会的发展 ${ }^{[1]}$ 。

\section{2 水资源可持续利用与水资源管理的重要性}

水资源是一切生命的生存、成长、繁殖的重要元素。水在人类社会的发展和人们的公共生活中发挥着极为关键、 重要的作用, 是保障所有发展得以进行的基础。根据当前对世界上的水资源利用的形势进行的调查和分析可以明显的 发现，缺水的问题是日趋严重的，这给人类社会的发展敲响了警钟也带来了一个难题。一方面，水资源的污染在工业 化的背景下不断的加速, 特别是一些化学工业的发展阶段对于水资源的损耗和污染极为严重; 与此同时随着全球气候 的变化, 地表水在温度升高的情况下蒸发率越来越高导致了严重的土地荒漠化现象，所以说在一些区域或一些国家土 地已经出现了严重的退化现象, 这给当地的人们的生活和生产带来了严峻的挑战甚至连最基础的居民饮用水都难以保 障。所以说在这种情况下我们必须要进行科学和合理的水资源的开发和利用, 以最大程度的提高水资源的利用率, 控 制水资源的过度消耗，减少水资源浪费，做到循环、可持续的水资源使用。与此同时还要采取有效的手段加强水资源 的可持续发展和水资源的循环利用, 并加强政府的相关行政管理部门对水资源的严格管理和控制, 以便从根本上解决 水资源损耗、水资源污染的问题, 推进社会发展和经济发展的节能、环保、可持续, 改善对水资源环境造成的污染和 破坏。为了更加合理和科学的利用水资源，我们每个公民都必须牢固的树立一种可持续发展的科学发展观，树立正确 有效的保护水资源的正确观念，从生活中做起有效的保护宝贵的水资源，通过多种方式、多种途径实现水资源的循环 利用。也就是说要不断的丰富水资源的多种用途, 比如在我们的日常生活中, 就可以把一些洗脸洗手的水来冲洗则所, 将一些淘米洗菜的水来进行植物的浇灌, 在我们洗手、洗脸的时候擦清洗用品的过程中要及时的管壁水龙头以便更好 的减少水资源的浪费和损耗。当然为了更有效的改善和提升水资源的管理，我们必须首先清楚的认识到可持续的、循 环利用的水资源管理对经济社会发展甚至是人类社会的发展的重要意义, 然后分析并找出现有的水资源管理工作中存 在的一些缺点和问题, 以便有针对性的解决这些问题应对具体的挑战, 彻底的实现可持续的、高质量的水资源管理 ${ }^{[2]}$ 。

\section{3 水资源利用过程中存在的问题}

\section{1 水资源污染问题严重}

我国地下水超采面积已经超过 18 万 $\mathrm{km}^{2}$ ，致使诸多地区的地面出现下沉、凹陷等系列问题，导致水资源的质量下 降。除此之外, 我国超过 $30 \%$ 的工业废水以及 $90 \%$ 以上的生活废水都有可能直接流入流域水资源中, 使得我国流域水资 源污染问题进一步严峻。

\section{2 过度开发和不合理利用水资源现象仍普遍存在}

随着全球的人口的逐渐增长人们的生活用水和工业发展用水的不断增长, 很多国家和地区出现了对水资源的过度 开发, 再加上一些地区缺乏有效的水资源使用的控制和管理就出现了极为严重的浪费、污染水资源的现象, 很多化工 企业直接将废水排入到河流湖泊当中, 造成了非常严重的水资源的污染问题, 并随着河流中水的流动, 污染物不断地 扩散逐渐形成了面积更大、污染更广的严重水资源污染。与此同时人们对于水资源特别是地下水资源的过度开采利用, 这种不可持续地使用水资源加剧了淡水资源的枯竭危机，人类社会的发展受到了非常严重的威胁。再加上许多人没有 养成在生活中节约用水以及保护水资源的意识和习惯, 在不使用水的时候水龙头没有及时的关闭, 导致大量的淡水资 源的白白流失，一个人如此，如果我国的上亿人口都这样那么我们每天要损失巨量的宝贵、珍惜的淡水资源。

\section{3 用水粗放、效率不高和浪费现象仍较严重}

目前中国的水资源管理工作当中是比较随意的, 没有一个系统科学的、严格高效的管理体系和管理计划, 导致了 人们的生活以及工业生产出现了大量的水资源的损耗和浪费的现象以及对水资源的严重污染的问题。许多化工企业再 
过去的粗放式经济发展方式中已经形成了一种习惯, 大量的使用水资源并且随意的排放工业废水, 他们忽视了水资源 的保护和再利用、再循环, 甚至说他们的头脑中根本就没有这种意识。这个问题也是当前的中国在水资源方面存在的 现状和面临的严峻挑战。我们必须要加强相关的管理体系的建立全面提高对水资源的保护和利用, 坚决惩罚那些浪费、 污染水资源的企业和个人, 加强宣传引导, 改变人们以及企业传统的用水理念和用水的方式, 提高人们对水资源的保 护和节约的正确认识。

\section{4 水资源管理工作受阻}

我国在水资源的管理方面涉及到了许多的部门，出现了多头管理、九龙治水的问题，考虑到目前中国在水资源管 理工作当中所面临的实际状况, 不难看到我国的水资源管理的相关部门缺乏科学的水资源管理的理念, 也缺乏正确的、 高效的管理方法, 这严重的阻碍了我国水资源的可持续发展。特别是在加强水资源的保护和治理水资源的污染的过程 中, 还会出现一些行政管理部门滥用权力的情况, 这严重的影响了水资源管理工作的良好发展。由于公众对水资源保 护和节约方面缺乏正确的、科学的认识, 因此水资源保护和节约的重要性被人们所忽视。 ${ }^{[3]}$

\section{4 水资源可持续利用与管理对策}

\section{1 完善水资源管理体系}

在目前的经济社会的发展过程中, 中国的诸多行业都实现了极为迅猛的发展和进步, 人们的生活水平也有了翻天 覆地的提升, 在这个背景下人们的生活和生产对于水的消耗越来越大, 而水资源的重复、循环利用的水平依然非常低。 为了更好的提高水资源的利用效率, 城市的建设体系和方案当中必须纳入城市的水资源管理系统, 只有这样才能实现 更高质量和更高水平的水资源管理做到水资源的节约和高效使用。

\section{2 提高水资源保护的意识}

水资源的合理开发利用以及保护是真正做到可持续发展的重要前提和基础, 而对水资源的高效利用是我国开展水 资源管理工作中最重要的一个管理目标。当然这个工作目标的实现需要有关部门和所有的公众的积极参与和共同努力 才可以达成。为了进一步的增强和提高人们对水资源的循环、重复、节约使用的认识, 相关部门需要通过电视、网络 和其他的渠道开展丰富多彩的、有趣生动的水资源保护的宣传。在这种氛围的营造下, 人们会自觉地、主动的加强水 资源节约和保护的意识, 共同携手努力建设水资源节约和保护的社会, 改变过去的那些水资源浪费和污染的错误行为。

\section{3 执行保护自然环境可持续循环的用水策略}

在中国大多数地区都普遍存在这样的问题, 地表水过度开发, 导致地表干旱严重, 此外很多地表水也会遭受到外 界不同程度的污染, 所以, 必须要科学合理配置水资源。

\section{4 完善水资源管理的调配制度}

相关部门要严格控制用水制度, 遵守协调发展、综合利用的原则, 合理控制用水量, 以此来确保流域水资源的合 理性利用。相关部门要制定切实可行的用水监督机制, 保证用户能够在严格的用水标准下有计划的用水 ${ }^{[4]}$

\section{5 结语}

经过本文的研究论证可以清楚地看到当前的社会发展过程中必须要强化对水资源的合理、充分、循环利用, 减少 对水资源的损耗和污染, 真正实现循环发展和可持续发展, 为人们的美好生活环境的营造打下坚实的基础。

\section{[参考文献]}

[1] 孟龙, 原军玲, 王君好. 水资源可持续利用与管理探析 [J]. 南方农机, 2019, $50(04): 225$.

[2]逯继新. 水资源可持续利用与水资源管理 $[\mathrm{J}]$. 黑龙江科技信息, 2017 (07) : 220.

[3] 黄丽. 水资源管理与可持续利用 $[\mathrm{J}]$. 现代农业科技, 2010(06): 268 .

[4]张金萍,曾赛星,杨旭, 齐国友.水资源可持续利用管理新论 [J].海河水利, 2004(04): 9-11.

作者简介: 宋光辉 (1980.3-), 男, 毕业院校: 新疆农业大学, 所学专业: 水利水电工程, 当前就职单位: 新疆塔里 木河流域巴音郭楞管理局开都河中游管理站, 职称级别: 工程师, 职务: 副站长。 